\title{
O IMPACTO INDUSTRIAL NA COMPOSIÇÃO QUÍMICA DAS ÁGUAS SUBTERRÂNEAS COM ENFOQUE DE CONSUMO HUMANO (RIO GRANDE, RS)
}

\author{
Nicolai Mirlean*, Maria Isabel Machado, Guillermo Martinez Osinaldi, Adriana Demoliner e Paulo Baisch \\ Departamento de Geociências, Fundação Universidade Federal do Rio Grande, CP 474, 96201-900 Rio Grande - RS
}

Recebido em 17/6/04; aceito em 10/12/04; publicado na web em 13/4/05

\begin{abstract}
INDUSTRIAL IMPACT ON CHEMICAL COMPOSITION OF GROUNDWATER: THE HUMAN CONSUMPTION ASPECT (RIO GRANDE, RS). The alteration in the quality of groundwater in the industrial zone of Brazil's southernmost state was assessed by a hydrogeochemical study. In 70-85\% of the studied area, fluoride, nitrate and phosphate in groundwater surpass the maximum limits for human consumption according to Brazilian environmental legislation. The chemical spectrum of contaminants and their spatial distribution show that fertilizer production processes are responsible for groundwater pollution. The natural conditions of the region are not favorable for minimal protection against infiltration of pollutants into the aquifer.
\end{abstract}

Keywords: groundwater; industries; pollution.

\section{INTRODUÇÃOO}

As águas subterrâneas são as principais fontes de água potável nas regiões com déficit de água superficial ou em localidades sem sistema centralizado de abastecimento de água. Em muitos locais ela é um complemento às águas superficiais, sendo muitas vezes consumida indiscriminadamente pela população, não levando em conta sua qualidade, o que acaba causando prejuízos para o bemestar dos consumidores. Geralmente os problemas com a qualidade da água subterrânea são maiores em regiões rurais devido à infiltração de agrotóxicos, fertilizantes, esgotos domésticos e excrementos de animais nos aqüíferos ou, diretamente, nos poços artesianos. Nestas regiões, os efeitos são mais significativos em seus consumidores, devido à ausência de outras opções de abastecimento $^{1}$. Entretanto, nas zonas industriais a preocupação com a qualidade da água subterrânea não é prioritária, visto que a população que reside nesta área é abastecida com água proveniente de sistema centralizado de água potável ${ }^{2}$.

Mas a realidade brasileira é bem diferente, apresentando nas proximidades das áreas industriais, a ocupação desordenada de uma população sem abastecimento centralizado de água potável e para a qual a água subterrânea é a principal fonte deste insumo, não ocorrendo nenhum tipo de controle da sua qualidade. Os poluentes que contaminam a água subterrânea das regiões industriais são mais complexos que os das áreas rurais e podem causar problemas sérios à saúde da população não somente através do consumo alimentação, mas também pelo uso na higiene pessoal ${ }^{3}$.

A zona industrial da cidade do Rio Grande caracteriza-se por apresentar ao lado de um complexo importante de indústrias, entre as quais fertilizantes e alimentos, áreas povoadas: vilas de pescadores, bairros e pequenos grupos de moradias não estruturadas, que ficam na zona de impacto das emissões das indústrias. Esta população, até a implantação de um sistema de abastecimento de água potável, o que ocorreu no ano de 2002, utilizava água subterrânea para consumo. Este hábito até hoje é verificado em algumas famílias por razões sócio-econômicas.

Esta zona industrial tem sido objeto de estudos principalmente por causa da dispersão aérea de fluoretos, produto das emissões

*e-mail: dgeonmir@furg.br decorrentes do processo de produção de fertilizantes ${ }^{4,5}$. Foram encontradas concentrações elevadas de fluoreto nas precipitações atmosféricas e na superfície do solo nesta região, bem como também foram detectados problemas de fluorose bovina e efeito corrosivo das precipitações sobre os isoladores elétricos das redes de alta tensão $0^{6,7}$.

A detecção de concentrações elevadas de fluoreto na água subterrânea em duas perfurações piloto, executadas previamente nesta zona industrial ${ }^{5}$, gerou a necessidade de um estudo mais detalhado da composição química das águas subterrâneas desta região.

Este artigo apresenta pioneiramente dados de concentração dos principais cátions e ânions da composição química da água subterrânea como resultado do impacto das emissões industriais, enfocando o uso doméstico desta água segundo a legislação atual brasileira $^{8,9}$.

\section{PARTE EXPERIMENTAL}

A zona industrial da cidade do Rio Grande localiza-se na península limitada por águas do estuário da Laguna dos Patos. O relevo é plano, com altitudes máximas de $4 \mathrm{~m}$ em áreas de dunas fósseis. O solo é arenoso não estratificado que, associado a um relevo baixo, leva à formação de um lençol freático na profundidade de 1 a $2 \mathrm{~m}$ em todas as partes da península. A água subterrânea descarrega-se na Laguna dos Patos diretamente ou através de valetas ao longo das estradas locais. A vegetação é, predominantemente, de origem herbácea com alguns bosques de eucalipto. Nesta zona encontram-se fábricas de produção de fertilizantes, tratamento de madeira e de produção de alimentos. Também ocorrem atividades portuárias e pesqueiras artesanais. Duas vilas de pescadores formam os principais núcleos de moradia na península, dentre os quais se encontram grupos esporádicos de moradias não organizadas (Figura 1).

A taxa de precipitação média sazonal na região do Rio Grande varia em torno de $15 \%$, não caracterizando um período de estiagem prolongada ou intensa precipitação ao longo do ano ${ }^{10}$. Em outubro de 2003, mês considerado como período de pluviosidade média anual, foram realizadas 21 perfurações ao longo do eixo da península, em locais de domínio público, utilizando um perfurador tipo hélice. Após a estabilização do nível da água na perfuração, a 


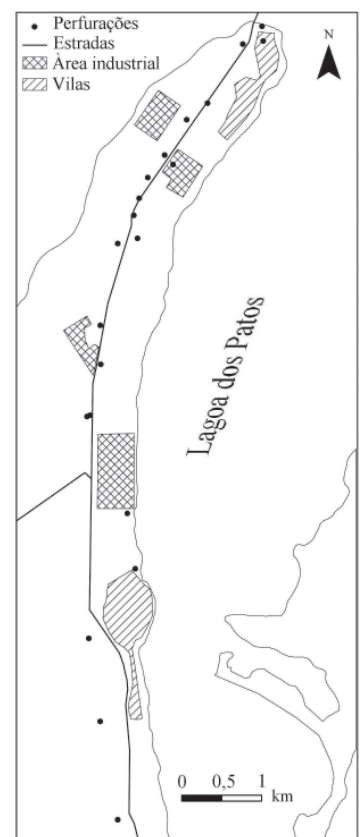

Figura 1. Localização da área de estudo

água era bombeada para um recipiente de vidro com capacidade aproximada de $1 \mathrm{~L}$ por meio de bomba de vácuo.

A água coletada foi levada ao laboratório, onde as medidas de $\mathrm{pH}$ (com eletrodo da marca Analion ${ }^{\circledR}$, acoplado a um $\mathrm{pH}$ metro Accumet $^{\circledR}$, modelo $\mathrm{n}^{\circ} 15$ ) e condutividade (condutivímetro da marca Oakton $^{\circledR}$, modelo WD-35607-10) foram realizadas imediatamente. Os valores de condutividade encontrados foram convertidos em sólidos totais dissolvidos (STD), utilizando-se um fator de conversão fornecido pelo manual do aparelho. A água foi filtrada a vácuo, através de membrana de éster de celulose $\left(0,45 \mu \mathrm{m}\right.$ Milipore $\left.{ }^{\circledR}\right)$, e conservada em frascos plásticos em geladeira à temperatura de $4{ }^{\circ} \mathrm{C}$.

A análise de ânions e cátions foi realizada por cromatografia iônica, em aparelho da marca Methrom ${ }^{\circledR}$, com supressão química, em coluna simples (Metrosep A Supp5-100), de dimensões 4,0 X $100 \mathrm{~mm}$. Para ânions, foi utilizada uma fase móvel de $\mathrm{NaHCO}_{3}$ $\mathrm{Na}_{2} \mathrm{CO}_{3}$, com velocidade de fluxo $0,6 \mathrm{~mL} \mathrm{~min}^{-1}$. Para cátions foi utilizada uma fase móvel de $4 \mathrm{mmol} \mathrm{L}^{-1}$ de acido tartárico e 0,75 mmol L ${ }^{-1}$ de ácido dipicolínico em coluna Metrosep C2-100. A curva padrão foi preparada com padrões da marca IsoSol, a partir de soluções estoque de $1000 \mathrm{mg} \mathrm{L}^{-1}$. As amostras foram diluídas, quando necessário, com água deionizada.

\section{RESULTADOS}

A água amostrada nas perfurações apresentou alta variação nos teores dos parâmetros de sua composição química (Tabela 1). Pelo STD, as águas estudadas encontram-se dentro da classe das águas doces (salinidade $<0,5 \%$ ) segundo a classificação da CONAMA ${ }^{8}$. No entanto, a variação do STD da água é alta e muda de uma perfuração para outra em até mais de 10 vezes.

$\mathrm{O}$ pH das águas analisadas também variou muito, de ácido com $\mathrm{pH}$ próximo a 4 , até $\mathrm{pH}$ de 7,7. O estudo apresenta dois grupos bem distintos, cerca de $70 \%$ das amostras tem $\mathrm{pH}<5,5$ e o restante, superior a 6,9 .

As águas estudadas têm como ânion principal sulfato ou cloreto, sendo que na maioria das amostras o sulfato foi o ânion predominante. Em águas ricas em sulfato, a concentração de cloreto foi duas ou mais vezes menor. Nas águas em que o ânion predominan-
Tabela 1. Principais cátions e ânions, $\mathrm{pH}$ e TSD (total de sais dissolvidos) em águas estudadas (21 amostras)

\begin{tabular}{lrrrr}
\hline $\begin{array}{l}\text { Compostos } \\
\text { químicos }\end{array}$ & Mínima & Máxima & Média & $\mathrm{CV}^{*}$ \\
\hline $\mathrm{pH}$ & 4,05 & 7,77 & 5,58 & 0,21 \\
$\mathrm{TDS}\left(\mathrm{mg} \mathrm{L}^{-1}\right)$ & 25,77 & 418,86 & 162,18 & 0,72 \\
$\mathrm{~F}^{-}\left(\mathrm{mg} \mathrm{L}^{-1}\right)$ & 0,04 & 4,79 & 2,10 & 0,66 \\
$\mathrm{Cl}^{-}\left(\mathrm{mg} \mathrm{L}^{-1}\right)$ & 0,25 & 85,20 & 20,49 & 1,07 \\
$\mathrm{NO}_{2}^{-}\left(\mathrm{mg} \mathrm{L}^{-1}\right)$ & $<0,01$ & 0,61 & 0,11 & 1,34 \\
$\mathrm{NO}_{3}^{2-}\left(\mathrm{mg} \mathrm{L}^{-1}\right)$ & $<0,01$ & 72,22 & 14,83 & 1,57 \\
$\mathrm{PO}_{4}^{3-}\left(\mathrm{mg} \mathrm{L}^{-1}\right)$ & 0,01 & 44,10 & 11,69 & 1,11 \\
$\mathrm{SO}_{4}^{2-}\left(\mathrm{mg} \mathrm{L}^{-1}\right)$ & 0,04 & 138,53 & 24,75 & 1,32 \\
$\mathrm{Na}^{+}\left(\mathrm{mg} \mathrm{L}^{-1}\right)$ & 2,26 & 130,11 & 25,97 & 1,39 \\
$\mathrm{NH}_{4}^{+}\left(\mathrm{mg} \mathrm{L}^{-1}\right)$ & $<0,01$ & 5,19 & 0,80 & 1,95 \\
$\mathrm{~K}^{+}\left(\mathrm{mg} \mathrm{L}^{-1}\right)$ & 1,5 & 63,55 & 12,56 & 1,16 \\
$\mathrm{Ca}^{2+}\left(\mathrm{mg} \mathrm{L}^{-1}\right)$ & 4,85 & 148,34 & 41,43 & 1,02 \\
$\mathrm{Mg}^{2+}\left(\mathrm{mg} \mathrm{L}^{-1}\right)$ & 0,96 & 18,18 & 7,56 & 0,81 \\
\hline
\end{tabular}

* CV - coeficiente de variação =SD/X; SD - desvio de padrão, $\mathrm{X}$ média.

te foi o cloreto, a concentração de sulfato foi dezenas de vezes mais baixa (geralmente menos de $1,0 \mathrm{mg} \mathrm{L}^{-1}$ ).

$\mathrm{O}$ terceiro ânion pela sua abundância foi o orto-fosfato, atingindo concentrações muito elevadas (até $44,1 \mathrm{mg} \mathrm{L}^{-1}$ ), quando comparadas com o "background" mundial das águas subterrâneas ${ }^{11}$, demonstrando forte influência antropogênica na composição da água da região em estudo. As águas ricas em fosfatos foram aquelas onde o sulfato foi o ânion predominante. $\mathrm{O}$ orto-fosfato e o sulfato têm correlação significativa, apresentando índice de correlação, $\mathrm{r}=0,56$ a um nível de significância $\mathrm{p}<0,05$, enquanto o cloreto e o fosfato não possuem correlação significativa.

$\mathrm{O}$ quarto ânion pela sua abundancia foi o nitrato, cujas concentrações variaram do limite de detecção 0,010 até $72,2 \mathrm{mg} \mathrm{L}^{-1}$. O ânion nitrato não apresenta nenhuma correlação significativa com nenhum outro ânion e ainda com o nitrito a correlação é bastante fraca $(\mathrm{r}=0,38 ; \mathrm{p}<0.1)$. As concentrações elevadas de nitratos foram encontradas em $40 \%$ das amostras e apresentaram correlação positiva significativa com sulfatos $(r=0,74, p<0,05)$ e negativa com $\mathrm{pH}(\mathrm{r}=-0,46 ; \mathrm{p}<0,06)$.

A concentração de fluoreto nas águas subterrâneas da região apresentou valores elevados (mais de 4,0 $\mathrm{mg} \mathrm{L}^{-1}$ ), e mesmo o seu valor médio pode ser considerado como muito alto $\left(2,1 \mathrm{mg} \mathrm{L}^{-1}\right)$. O fluoreto tem correlação positiva com fosfato $(r=0,69 ; \mathrm{p}<0,05)$ e negativa com $\mathrm{pH}(\mathrm{r}=-0,49 ; \mathrm{p}<0,06)$.

O cálcio foi o principal cátion em $75 \%$ de amostras analisadas, o que não é normal para águas subterrâneas desta região, com clima subtropical e solos arenosos ${ }^{12}$. Ele foi o cátion de maior influência na concentração dos STD das águas estudadas $(r=0,82$; $\mathrm{p}<0,05$ ), e o que tem maior correlação com orto-fosfato $(r=0,82$; $\mathrm{p}<0,05)$ e nitrato $(\mathrm{r}=0,52 ; \mathrm{p}<0,05)$, o que também não é comum para águas naturais onde cálcio se correlaciona principalmente com sulfato.

O sódio foi o segundo cátion responsável pela concentração dos STD das águas, no entanto apresentou correlação significativa somente com cloreto $(\mathrm{r}=0,96 ; \mathrm{p}<0,05)$, o que é característico para as águas doces da região. Algumas amostras apresentaram-se anomalamente enriquecidas com potássio, sendo sua concentração várias vezes superior à concentração do íon sódio. $\mathrm{O}$ potássio tem correlação significativa somente com íon amônio $(r=0,59 ; \mathrm{p}<0,05)$.

A variação espacial dos parâmetros físico-químicos da água subterrânea apresentou uma grande heterogeneidade (Figura 2). O 

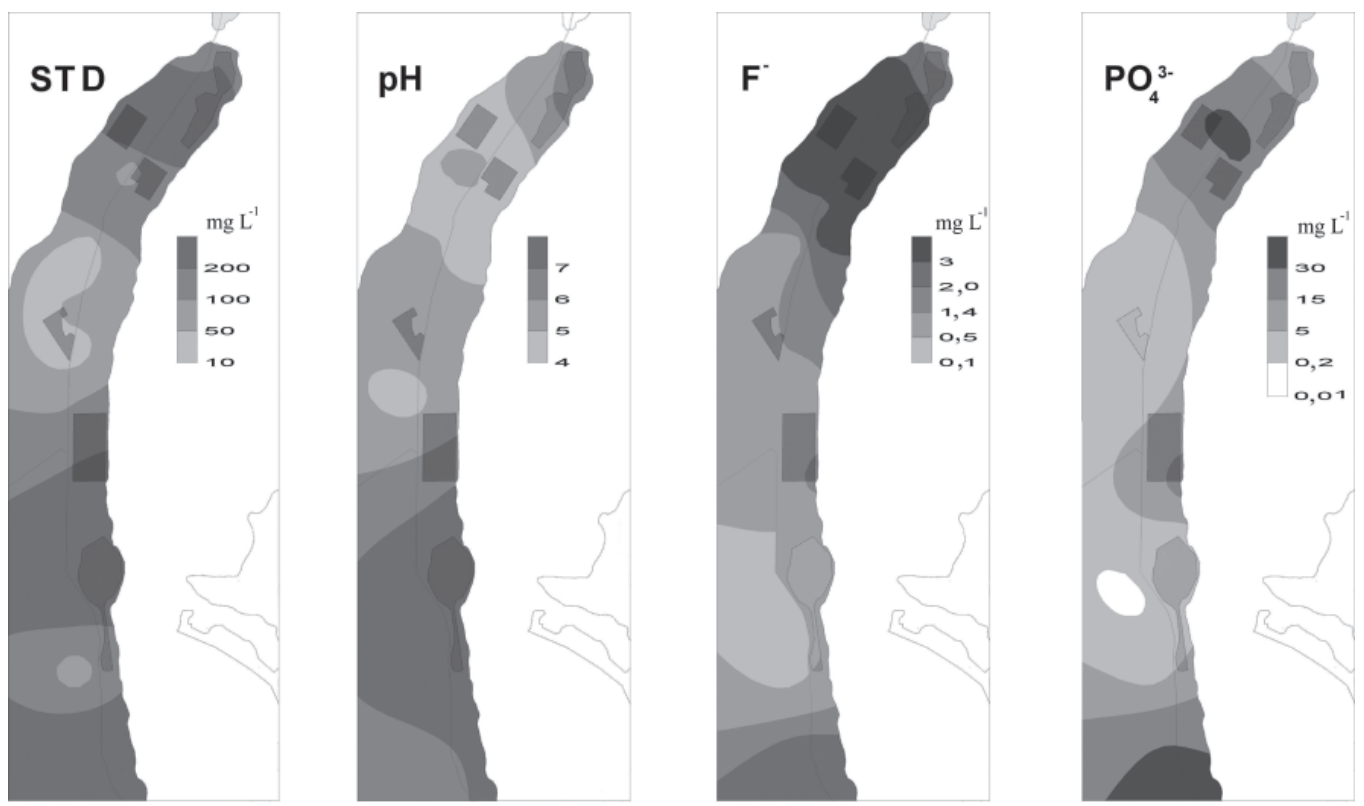

Figura 2. Distribuição do TSD, pH, $\mathrm{F}^{-}$e $\mathrm{SO}_{4}^{2-}$ na água subterrânea

STD da água foi maior (acima de $100 \mathrm{mg} \mathrm{L}^{-1}$ ) nas porções norte e sul da península, enquanto que na parte norte essa anomalia tem seu centro na zona amostrada próxima às indústrias de produção de fertilizantes. $\mathrm{O}$ pH da água subterrânea apresentou duas anomalias, com pH acentuadamente ácido, nas porções norte e central da península, estando os centros de ambas as anomalias na posição das indústrias de fertilizantes e terminais graneleiros. Os íons fluoreto e orto-fosfato apresentaram uma distribuição semelhante, com uma anomalia isocêntrica na porção norte (indústrias de fertilizantes) e concentrações elevadas no extremo meridional da porção sul da península. Os outros ânions e cátions também mostraram distribuição espacial muito heterogênea, sempre revelando valores mais discrepantes na zona onde estão localizadas as indústriais de fertilizantes.

\section{DISCUSSÃO}

A composição das águas subterrâneas na planície costeira do extremo sul do Brasil é influenciada por peculiaridades pedológicas e climáticas típicas da savana meridional da América do Sul ${ }^{11}$. A alta taxa de precipitação, a composição quartzo-arenosa dos solos pobres em cátions alcalino-terrosos $\left(\mathrm{Ca}^{2+}, \mathrm{Mg}^{2+}\right)$ e o relativamente denso carpete de vegetação herbácea geram condições de formação de águas subterrâneas muito doces (STD $<100 \mathrm{mg} \mathrm{L}^{-1}$ ) e levemente ácidas (pH 5,5-6) tendo como íons principais sódio e cloreto.

As concentrações médias dos íons estudados e do STD na água subterrânea da zona industrial diferenciam-se muito das características da composição do "background" da região, o que pode ser visualizado no diagrama do espectro comparativo da composição química média das águas subterrâneas (Figura 3). Somente a concentração de cloreto nas águas subterrâneas da zona industrial corresponde ao valor do "background". Deveríamos ter uma contribuição muito grande deste ânion, pela atividade industrial, para que ela causasse um aumento significativo na composição da água subterrânea, já que este é um íon normalmente presente nas águas subterrâneas da região. Os outros ânions estudados tiveram um acréscimo, em relação aos níveis de "background", para as águas subterrâneas da região industrial, de algumas unidades de vezes para STD, dezenas de vezes para fluoreto e sulfato, centenas de

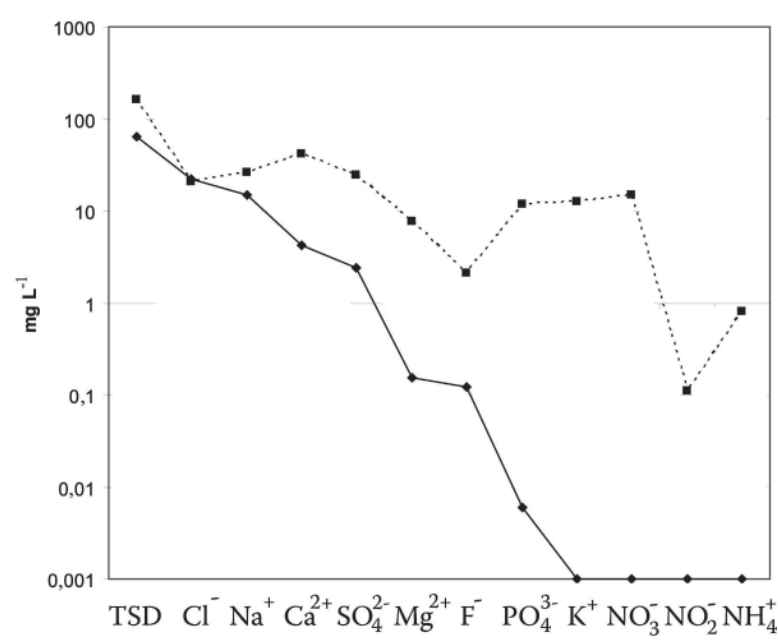

Figura 3. Espectro comparativo da composição química das águas subterrâneas na área do "background" (linha continua) e na área industrial (linha tracejada). Os valores de "background" foram obtidos pela analise da água subterrânea nas proximidades da reserva natural do "Taim” a 80 km da área industrial

vezes para nitritos e amônio e até mais de mil vezes para ortofosfato, potássio e nitratos. Este teor tão elevado para o íon ortofosfato é verificado em cerca de $80 \%$ dos pontos amostrados, onde a concentração média de orto-fosfato superou em até 700 vezes o valor de "background" da região.

Na área industrial da cidade do Rio Grande são utilizados diferentes processos tecnológicos industriais e portuários, que podem interferir na qualidade da água subterrânea. Verifica-se, pela distribuição espacial dos compostos químicos estudados da água subterrânea da região, que os maiores valores encontrados estão localizados próximos a indústrias de fertilizantes. No processo de acidulação da rocha fosfática para a produção do superfosfato, o fluoreto é um importante íon participante das emissões desta reação. O processo de produção de fertilizantes envolve reações muito ácidas, e as águas subterrâneas destes locais em sua grande maio- 
ria, principalmente próximas às indústrias de fertilizantes, apresentaram seus valores mais ácidos. Sendo assim, pode-se afirmar que as indústrias de fertilizantes têm uma contribuição principal de impacto químico nesta área.

No entanto, ao longo da área estudada foram encontrados alguns valores discrepantes, caracterizando zonas de alta concentração de compostos químicos, podendo ser classificadas como "anomalias isoladas", originadas por processos de deposição de compostos afastados das emissões provenientes das fábricas de fertilizantes, ou por outros tipos de atividades industriais. Assim, o valor de baixo $\mathrm{pH}$ na parte central da península pode ser atribuído, provavelmente, a depósitos de carvão ao ar livre na proximidade deste ponto de coleta (Figura 2). Na mesma parte da península, os valores discrepantes de fluoreto e fosfatos ocorrem numa zona próxima ao terminal portuário de carga e descarga de matéria-prima, operação esta que acarreta muita perda desse material, que é finamente pulverizado. Além disso, muitos produtos utilizados como matéria-prima são armazenados ao ar livre, em grandes pilhas, provocando a lixiviação destes compostos químicos diretamente para o aquíffero. Esta afirmativa é comprovada pela presença de altas concentrações de cálcio, potássio e nitratos, originários do produto a granel estocado, e pela relativa baixa concentração de sulfatos, que só volta a ser significativa nas proximidades da indústria de fertilizantes. O ácido sulfúrico é utilizado na reação de acidulação da rocha fosfática. A deteç̧ão de altos valores de fluoreto e ortofosfato na parte sul da área de estudo, onde não existe nenhuma atividade industrial, é, provavelmente, causada pela atividade da barreira geoquímica na atmosfera ${ }^{13}$. Neste local, as emissões ácidas das fábricas carreadas pela atmosfera por ventos de NW encontram as massas de ar ricas em "spray" de água marinha, neutralizando-se e resultando na precipitação dos poluentes. Esta hipótese está fundamentada nas concentrações relativamente elevadas de cloreto e sódio e pelo caráter neutro ou levemente alcalino das águas subterrâneas desta área.

Atualmente, na cidade do Rio Grande, a fonte principal de água potável é o sistema centralizado de fornecimento, porém verificam-se muitas zonas onde a água subterrânea é a principal fonte de água potável. A legislação brasileira contempla dois documentos principais que regulam a qualidade da água para consumo huma$\mathrm{no}^{8,9}$. Pelo modo como a população local usa e trata a água subterrânea da zona industrial, deve-se considerá-la como uma água da Classe Especial destinada ao abastecimento doméstico sem prévia ou com simples desinfecção, conforme a resolução CONAMA ${ }^{8}$. No entanto, por alguns parâmetros analisados a água subterrânea do local não está enquadrada dentro dessas normas. Esta água também não se encontra dentro de alguns dos limites de qualidade estabelecidos pelo Ministério da Saúde ${ }^{9}$ para água potável. Pela resolução CONAMA, a água ultrapassa o limite aceitável de concentração de nitrato (em termos de N), em 25\% das perfurações; é demasiado ácida em $70 \%$ das perfurações; ultrapassa o limite sanitário de fluoreto em $80 \%$ das amostras e a concentração de ortofosfato (em termos de P) está acima do limite aceitável, em $85 \%$ das perfurações realizadas. Pelos parâmetros indicados pelo Ministério da Saúde e considerados no presente estudo, as concentrações de nitrato (em termos de $\mathrm{N}$ ) e fluoreto encontradas na maioria dos pontos não classificam esta água como potável. A ultrapassagem dos limites desses componentes acima dos valores estipula- dos pelas normas em discussão varia em algumas unidades de vezes para fluoreto e nitrato e até centenas de vezes para orto-fosfato. Esses dados causam preocupação, quando se considera a área povoada da península.

\section{CONCLUSÃO}

Conclui-se pela alteração encontrada na composição iônica das águas subterrâneas e pelas correlações entre os ânions e cátions, bem como pela distribuição espacial dos poluentes no aqüífero, que a produção de fertilizantes na zona industrial do Rio Grande tem grande influência na qualidade da água subterrânea desta região. As anomalias dos compostos e elementos químicos na água subterrânea são derivadas principalmente por precipitação das emissões industriais, tanto nas proximidades das suas fontes como afastadas destas. Sendo muito provável para esse último caso, que essa precipitação seja resultado da interação dessas emissões atmosféricas com massas de ar marinho. Também ocorrem anomalias isoladas, resultantes da lixiviação de poluentes diretamente dos depósitos de produtos e de matéria-prima. Pelas normas estatais de qualidade da água, na maior parte do distrito industrial da cidade do Rio Grande a água não se encontra com qualidade aceitável para consumo humano. Como a composição litológica dos solos do local não oferece qualquer proteção natural do aquífero contra a infiltração dos poluentes na água subterrânea e como a produção de fertilizantes é um investimento consolidado na região, é importante que a população seja orientada para a não utilização desta água subterrânea para consumo humano.

\section{AGRADECIMENTOS}

Ao Conselho Nacional de Desenvolvimento Científico e Tecnológico (CNPq) pelo apoio financeiro.

\section{REFERÊNCIAS}

1. Melian, R.; Mirlean, N.; Gouriev, A.; Moraru, K.; Radstake, F.; Hydrogeology Journal 1999, 7, 188.

2. Saet, Y. E.; Environmntal Geochemistry, Nedra: Moscow, 1991.

3. Kuprianov, V. V.; Hydrogeological Aspects of Urbanization, Hydrometeoizdat, Sant-Petersburg, 1986.

4. Brigoni, S. F.; Relatório Interno, Departamento de Meio Ambiente, Divisão de Qualidade do Ar, Porto Alegre, 1983.

5. Mirlean, N.; Casartelli, M. R.; Garcia, M. R. D.; Quim. Nova 2002, 25, 191.

6. Vanz, A.; Mirlean, N.; Baisch, P.; Quim. Nova 2003, 26, 25.

7. Riet-Corrêa, F.; Oliveira, J. A.; Méndez, M. C.; Schild, A. L.; Pesquisas Veterinárias Brasileiras 1983, 3, 107.

8. CONAMA - Conselho Nacional do Meio Ambiente; Resoluções Conama, 1992.

9. Ministério da Saúde; Portaria $N^{o} 518$, de 25 de março de 2004, Diário Oficial da República Federativa do Brasil, Brasilia.

10. Krusche, N.; Saraiva, J. M. B.; Reboita, M. S.; Normais climatológicas provisórias de 1991 a 2000 para Rio Grande, RS, FURG, Rio Grande, 2002.

11. Drever, J. I.; Geochemistry of Natural Waters: surface and groundwater environments, Prentice-Hall: London, 1997.

12. Perelman, A. I.; Kasimov, N. S.; Geochemistry of Landscapes, Astrea: Moscow, 1999.

13. Perelman, A.I.; Geochemistry of Hypergenese, Nedra: Moscow, 1972. 